\title{
Assisting JHS Form One Pupil's to Add Unlike Fraction Using Cuisenaire Rod and Paper Folding: A Case at Chamba M/A Junior High School
}

\author{
Jagri Bagyepu Bernard ${ }^{1,}$, , Aloliga Golbert ${ }^{1}$, Susuoroka Gabina ${ }^{2}$ \\ ${ }^{1}$ Mathematics Department, St Vincent College of Educatipon, Yendi, Ghana \\ ${ }^{2}$ Mathematics Department, Nusrat Jahan Ahmmadiyya (NJA) College of Education, Wa, Ghana
}

Email address:

bernardjagri@gmail.com (J. B. Bernard), aloliga@mail.com (A. Golbert), susuorokag@yahoo.com (S. Gabina)

${ }^{*}$ Corresponding author

\section{To cite this article:}

Jagri Bagyepu Bernard, Aloliga Golbert, Susuoroka Gabina. Assisting JHS Form One Pupil's to Add Unlike Fraction Using Cuisenaire Rod and Paper Folding: A Case at Chamba M/A Junior High School. Teacher Education and Curriculum Studies. Vol. 5, No. 3, 2020 , pp. 53-60. doi: $10.11648 /$ j.tecs.20200503.12

Received: November 12, 2019; Accepted: February 3, 2020; Published: June 28, 2020

\begin{abstract}
The purpose of the study was meant to assist Junior High School form one pupils in Chamba M/A JHS to add unlike fractions. The study adopted action research design, as simple random sampling technique was used to select a sample of 45 pupils. Whilst, test (pre-test and post-test) and observation was used as instrument to collect data. Findings made from the study indicated mathematics teachers taught mathematics abstractly with less involvement of pupils. It was revealed that the intervention couple with the teaching learning resources used, it encouraged pupils' participation during teaching and learning, as such their knowledge in unlike fractions improved significantly. The researcher recommend adequate preparation and careful selection of teaching methods and activities should be given much attention so as to enhance smooth delivery and pupils participation in lessons. Secondly, quizzes and group works should be encouraged to motivate pupils' active participation in mathematics lessons. Mathematics teachers should do well to get appropriate teaching and learning resources and make efforts to use them in class to enhance better understanding. The Ghana Education Service in consultation with the Ministry of Education should organize in-service training from time-to-time for Mathematics teachers to upgrade their knowledge on the teaching of Mathematics. Finally, Ghana Education Service should also provide teaching and learning resources (Manipulatives) needed to all schools or pay teaching and learning materials allowances to enable teachers acquire materials for their lessons.
\end{abstract}

Keywords: Cuisenaire Rods, Constructivist, Physiognomies, Hypothetical Lens, Fractions, Manipulatives, Paper Folding

\section{Introduction}

In Ghana, the Free compulsory Universal Basic Education (FCUBE) policy and the curriculum showcase that "all students can learn mathematics and that all need to learn mathematics" [1], this has enhanced enrolment of children with different upbringings, learning abilities, cultures, and learning styles in the mathematics classroom today. The admission of children with such different physiognomies in classroom situations stance tasks to mathematics teachers. Mathematics teachers are confronted to deliver uniform learning chances and care for youngsters with diverse skills, mental aptitudes, and learning flairs.

Undeniably, the educational restructurings respectively in Ghana were inspired by the need to offer for multiplicity and to brand education more significant. The mathematics curriculum content was reviewed to equip pupils with mathematical expertise and talents to be acceptable of entering into distinctive courses of interest. One hypothetical lens that led the modification of the recent mathematics curriculum to feed for variety in learning is constructivism. The adoption of constructivism as a philosophy in the mathematics curriculum process is based on the distinguishing that there are distinctive ways of intellectualizing existence [4]. The constructivist principles give space for mental multiplicity and allow the probability of resolving hitches in diverse means [4]. Mathematics teachers, who are to ensure effective use of the mathematics 
curriculum, are to accelerate students' composition of mathematical knowledge from changed viewpoints. They are also to design a classroom philosophy that allows students to enthusiastically discover diverse problem solution approaches to develop the skills defined by the mathematics curriculum. Constructivism as a hypothetical lens for Ghana's curriculum design and application procedure is a facility for diversity - numerous exhibitions, answers, learning faculties and flairs [4].

Among the numerous ways of earning the mathematical learning necessities in a different classroom make-up is using various fashions of illustrations that combine pupil's previous proficiencies and curiosity in answering mathematical problems [4].

Fractions remain well thought out as an important mathematical field for students [5]. Practical and theoretical understanding of fractions are critical for encouraging more progressive mathematical concepts in areas like algebra, and for contributing in everyday accomplishments such as preparing food and personal finance [6-7]). Besides, it was also suggested pupils in basic schools should be capable to meritoriously carry out procedures including fractions, but also noticed fractions are part of major trouble for many pupils in mathematics [7]. While many pupils scuffle with fractions, pupils with infirmities incline to experience greater confronts with fractions $([8,9])$.

To help the theoretical and practical knowledge of fractions, scholars and professional organizations recommended diverse but connected instructional approaches. [10, 11] approved precise teaching as an evidence-based practice in mathematics for pupils with infirmities; scholars also encouraged for use of explicit teaching learning Resources (TLR) for pupils with knowledgeable and growing infirmities $[12,13]$, as well as the [16], noted the importance of using TLRs to support fraction instruction. Finally, scholars found a continuing progression of instruction - such as the Concrete-Representational-Abstract (CRA) - to be effective in the teaching of fractions [14, 15].

The use of CRA teaching material is a showcase practice for pupils with learning difficulties that increase theoretical and practical knowledge in a diversity of mathematics areas, including fractions $[16,17,9]$. The CRA instructional sequence involves a gradual sequence of teaching across three stages. Concrete manipulatives (e.g., Cuisenaire rods, paper folding) are used in the first stage to tangibly demonstrate a mathematical concept in combining with abstract mathematical notation. As pupils gain mastery in the concrete stage, the physical manipulatives are substituted by visual re-presentations (e.g., students draw representations). Pupils complete the last stage using only theoretical mathematical symbolization and mathematical approaches. Precise teaching is rooted within the CRA instructional outline as teachers model and think aloud (i.e., recount or express their problem-solving method), continue to support, practice, and then provide independent practice during each stage of teaching [18-21] emphases mathematics in the basic schools in Ghana, is not taught the way it was suppose to be taught. Teachers taught using the teacher centred method without using manipulatives. Instead of pupil centred method with all the necessary manipulatives to enhance pupils' participation and understanding. Besides, many basic schools have no access to well establish mathematics laboratories and libraries to assist teachers teach the subject practically. Hence, this study intends to improvise Cuisenaire rods and paper folding to involve the pupils more in the teaching and learning of addition of unlike fractions, since the most mathematics teachers taught mathematics abstractly.

Before pupils can understand the idea of addition of fractions with different denominators, there is the need for them to grasp the concept of like fractions very well to enable them to deal with the addition of unlike fractions [22]. Besides, [23] defined unlike fractions as two or more fractions, which have different denominators. He went on to say that, when dealing with unlike fractions, you could either have only two fractions or more than two. He gave examples as: $5 / 6,2 / 3,1 / 4,3 / 5$.

Cuisenaire rods are the best teaching and learning materials that will motivate pupils to add fractions with different denominators [24]. He said that, children admire colours and will like to use Cuisenaire rods to add unlike fractions. When using Cuisenaire rods to add unlike fractions, (during face-to-face interactions), you have to let the pupils choose any rod or set of rods to be their "whole", For example, orange and dark green. Let the pupils make up as many rods as they can use rods of one colour only. Example, all red or brown, the rods must be of the same length as the original whole chosen.

\begin{tabular}{|c|c|c|c|c|c|c|c|c|c|c|c|c|c|}
\hline \multicolumn{6}{|c|}{ Orange } & & & & \multicolumn{5}{|c|}{ Dark green } \\
\hline \multicolumn{6}{|c|}{ Brawn } & \multicolumn{8}{|c|}{ Brawn } \\
\hline \multicolumn{3}{|c|}{ Purple } & \multicolumn{3}{|c|}{ Purple } & \multicolumn{4}{|c|}{ Purple } & \multicolumn{4}{|c|}{ Purple } \\
\hline Red & & & $\mathrm{Re}$ & & $\operatorname{Rec}$ & $\mathrm{Re}$ & & $\mathrm{Re}$ & & $\operatorname{Re}$ & & Red & \\
\hline $\mathrm{W} \mid \mathrm{W}$ & $\mathrm{w}$ & $\mathrm{W}$ & $\mathrm{W}$ & $\mathrm{W}$ & $\mathrm{W} \mathrm{w}$ & $\mathrm{W}$ & W & $\mathrm{W}$ & & $\mathrm{W}$ & $\mathrm{W}$ & W & W \\
\hline
\end{tabular}

Figure 1. Demonstration of Cuisenaire rod.

From the above figure, the pupils can identify the following:

i. Two browns make up the orange and dark-green as a whole

ii. Four purples make up two browns

iii. Four reds make up brown.

iv. Eight reds make up the orange and dark-green as a whole

v. Two whites make up one red

vi. Four whites make up one purple

vii. Eight whites make up one brown

viii. Sixteen whites make up orange and a dark-green as a whole.

[25] paper folding activity is another useful teaching and learning material that will motivate pupils to add unlike fractions. Therefore, when pupils cut out their papers to fold and compare in order to solve unlike fractions, it goes a long way to promote good understanding of the topic. 


\section{Literature}

[24] holds a view that the failure of teachers to upgrade themselves to meet the new educational reforms lead to the causes of pupils' inability to add unlike fractions appropriately. It is obvious that, most teachers still rely on the old methods of teaching. To him, teachers do not integrate their lessons with teaching and learning materials to motivate pupils to learn. As the popular saying goes "when I hear I forget, when I see I remember and when I do, I understand". Hence teachers need to give way for pupils to get closer and manipulate with the teaching and learning materials to encourage them to develop interest in mathematics.

While, [26] stated language is a limiting factor that leads to pupils' inability to add fractions. This factor stem from errors committed as a result of reading disabilities, poor comprehension and carelessness. [27] believes that the pupils' inability to add unlike fractions is attributed to pupils' inattentiveness in class. From his view, pupils do not normally pay attention in class during lesson delivery. This is why they claim "mathematics is difficult" and this makes them develop negative attitude towards the subject. It is the responsibility of teachers to encourage, motivate and assist learners to overcome this negative attitude.

In addition, [24] said the causes of the pupils' inability to add unlike fractions is attributed to teachers lacking the teaching techniques and methodology to enable pupils to learn with zeal. This is due to the fact that, teachers stick to the lecture method of teaching and which does not involves the use of teaching and learning materials to motivate pupils to learn. Instructional aids when properly used make teaching and learning understandable and enjoyable [28]. It is however unfortunate that the use of those teaching and learning materials are not found in the schools which make teaching and learning of mathematics not friendly. Also, some teachers rush to symbolization and operation of fractions without developing strong conceptual understanding of them. This event eventually leads pupils having problems in adding fractions [29].

\section{Methods Used to Add Fractions with Different Denominators}

Many writers have come out with different methods of adding unlike fractions. For instance, [30] suggested that, considering the top bits referred to as the numerators and the bottom bits known as the denominators can solve addition of unlike fractions. He explained that a situation where fractions have unlike denominators, they can be added by adjusting their denominators so that they can be added easily. For example: $1 / 2+1 / 4$. For $1 / 2$, you multiply both the numerator and the denominator by $2.1 / 2 \mathrm{x}^{2} / 2=\frac{2 \times 1}{2 \times 2}=2 / 4$.

We can now add the two fractions since their denominators are the same.

$$
2 / 4+1 / 4=\frac{2+1}{4}=3 / 4
$$

According to [32], Fractions with different denominators such as $2 / 3$ and $3 / 4$ are called unlike fractions. This is because the denominators 3 and 4 are of different values. The denominator 3 of the fraction 2/3 means 2 parts taken out of a total of 3 of something whereas the denominator 4 of the fraction $3 / 4$ means 3 parts taken out of 4 . From this, it can be of different values that bring about the name unlike fractions. [31] stated that fractions can only be added if they have the same denominator. That is $1 / 8+2 / 8$. Therefore, to add fractions with different denominators, you find the Least Common Multiple (LCM) of the denominators. A set of fractions has many common multiples of their denominators. For instance, the common multiples of the denominator of $2 / 3$ and $3 / 4$ are $3=3,6,9,12,15,18,21,24,27$ and $4=4,8$, $12,16,20,24,28,32$. Least Common Multiples (LCM) is the least number that can be divided evenly by all the denominators of the fractions you are adding. As you see the least common multiple (LCM) of the denominators 3 and 4 and is 12 (product of the two denominators) will then be worked out this way.

$$
2 / 3+3 / 4=\frac{8+9}{12}
$$

Divide the LCM (12) by the denominator of the first fraction and multiply it by the numerator of that same fraction and write the product down. Do the same to the second fraction. $2 / 3+3 / 4=\frac{8+9}{12}$. You then add the products, that is $8+9=17$ over the LCM, ${ }^{17} / 12$ which is an improper fraction. You further divide 17 by 12 to get a mixed fraction $1_{12}^{5}$ and that is the final answer.

[33] used the following method in solving additions of unlike fractions. He first find the least common multiple of the unlike denominators. Example $2 / 3+1 / 4$

Choose a whole that can split into four (4) equal parts and at the same time can split into three equal parts. This made us to choose a rod with length equal to the least common multiple (LCM) of three (3) and four (4), thus 12.

Here, we can choose black and yellow whole.

\begin{tabular}{|l|l|}
\hline Black & Yellow \\
\hline
\end{tabular}

Figure 2. LCM.

He also used purple to represent the number four (4) and green for the number three (3). Thus

Take two (2) purple for $2 / 3$ and one (1) green for $1 / 4$. Thus

\begin{tabular}{|c|c|c|c|c|}
\hline \multicolumn{2}{|l|}{} & \multicolumn{2}{c|}{ Yellow } \\
\hline Black & \multicolumn{2}{|c|}{ Purple } & \multicolumn{2}{|c|}{ Purple } \\
\hline Purple & Green & & Green & Green \\
\hline Green & \multicolumn{2}{|c|}{ Gren } \\
\hline
\end{tabular}

\begin{tabular}{|c|c|c|}
\hline Purple & Purple & Green \\
\hline $2 / 3$ & $1 / 4$ \\
\hline \multicolumn{2}{|c|}{} \\
\hline
\end{tabular}

Figure 3. Modeling of $2 / 3$ and $1 / 4$.

Change the two purples for eight whites and the green for 
three whites. Thus

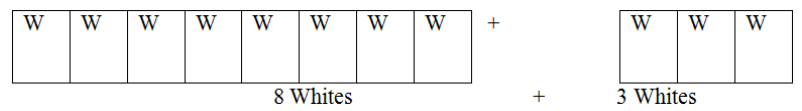

Figure 4. Illustration of the uses of Cuisenaire rod.

Joining them, we have eleven (11) whites compared to the original whole. Working procedure $=2 / 3+1 / 4=8 / 12+3 / 12=\frac{8+3}{12}$ $=\frac{11}{12}$

[35] stated a principle that if $\mathrm{a} / \mathrm{b}$ and $\mathrm{c} / \mathrm{d}$ are fractions of different denominators, then $\mathrm{a} / \mathrm{b}+\mathrm{c} / \mathrm{d}={ }^{\mathrm{ad}} / \mathrm{bd}+{ }^{\mathrm{bc}} / \mathrm{bd}=\frac{a d+b c}{b d}$

[26] gave sequential procedure for the addition of unlike fractions.

a) Find the Least Common denominator

b) Convert all fractions into equivalent fractions that have the least common denominator.

c) Add the resulting like fractions.

d) Factor both the numerator and the denominator of the resulting fraction and reduce to the least terms if possible.

For example $2 / 3+5 / 6$, we take our least common denominator to be 6 .

For $2 / 3$, we need to multiple both the numerator and the denominator by 2 . Thus, $\frac{2 \times 2}{3 \times 2}=\frac{4}{6}$

We now add the fractions since their denominators are the same; $4 / 6+5 / 6=\frac{4+5}{6}=9 / 6$ or $1 \frac{3}{6}$

\section{Material and Methodology}

The study adopted action research design. Action research is a way of providing immediate solution to a classroom problem that the researcher identified [32, 33]. The population of the study was made up of 216 pupils in Chamba M/A Junior High and a sample size for the study was 45 pupils using simple random sampling technique through balloting to select twenty-two (22) boys and twentythree (23) girls.

Research instruments refer to the tools used by the researcher to enable him/her gather information about the problem. The researcher used test and direct observation as research instruments.

Observation is a research tool used to gather data where the researcher assumes the role of an observer but carefully notes down the behavior of the pupils during lesson delivery. Observation involves looking at and listening to an action of a person in a given situation with attention and concentration $[34,35]$. The researcher observes the pupils by watching and listening to the way pupils ask and answer questions before, during and after intervention process. The researcher realized that pupils have problems with addition of unlike fractions during lesson delivery and decided to institute other research instrument to enable her to describe the behavior of pupils as accurately as possible. The tool was used because it relatively easy to use, less costly and is able to capture information that cannot be gathered using other research instrument such as questionnaire. However, the main weakness of this tool is that it is prone to observer's bias and misinterpretation. The results obtained through observation may not be reproducible [36] \& [37].

Test items are issuing of questions in any forms for pupils to give responses based on the demands of the questions [36].

The test that was used to ascertain the pupils' challenges is called the pre-test. After the pre-test, an intervention was administered which was followed by another test to ascertain whether there have been an improvement or not and this test is known as the post-test. The researcher chose test because it is used to diagnose the extent of the problem and also use to determine the effectiveness of the intervention that was administered to address the problem, besides test results are reliable.

The procedures that were employed to collect data for the study are presented in three folds: Pre-intervention, intervention and post-intervention.

In other to diagnose the extent of the problem, the researcher designed and conducted a teacher made test made up of five questions involving addition of fractions with different denominators. The pupils were allowed for some time to work out the test items. The papers were then collected and marked. From the scores, about seventy percent (70\%) of the pupils scored marks less than the pass mark of five (5) while about thirty percent $(30 \%)$ scored marks above the pass mark of five (5). These results informed the researcher the pupils really had a problem on additions of fractions with different denominators and have to plan and implement an intervention to assist the pupils to improve in performance in fraction with different denominators.

Intervention is a set of strategies used to improve pupil's performance in adding unlike fractions $[21,22,20]$. In this study, some concrete materials were gathered and activities planned to teach the pupils. The researcher made the lesson very real and practical by using Cuisenaire rods and paper folding as teaching and learning materials to enhance pupils understanding of addition of unlike fraction.

Under this activity, the researcher used Cuisenaire rods to guide pupils to solve problems involving addition of unlike fractions. Cuisenaire rods are made up of different colours. The researcher guided the pupils in identifying the colours of the rods and their units. Below are the colours of the rods and their units.

Colours and their units

\begin{tabular}{|l|l|l|l|}
\hline White & 1 Unit \\
\hline Red & 2 units \\
\hline Light green & 5 units \\
\hline Purple & 5 units \\
\hline Yellow & 6 units & \\
\hline Dark green & 7 units \\
\hline Black & \\
\hline Brown & \\
\hline Blue & \\
\hline Orange & \\
\hline
\end{tabular}




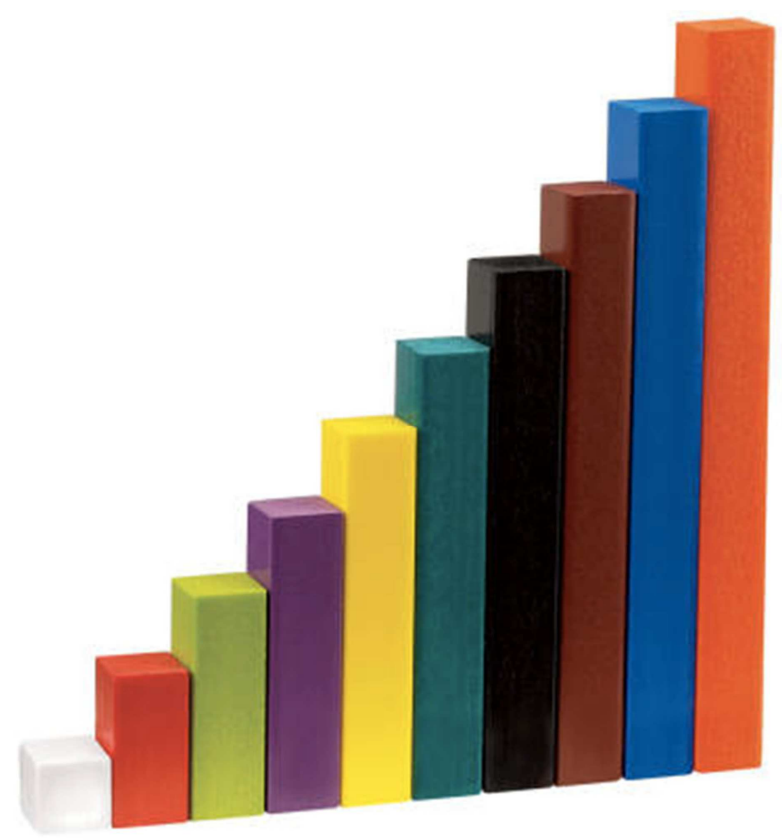

Figure 5. Identification of Cuisenaire rod.

The researchers then guided the pupils to solve $2 / 3+1 / 4$ by asking them to find the least common multiple of the denominators of the fractions. Pupils were guided to list down the multiples of 3 and 4 .

$3=3,6,9,12,15, \ldots$

$4=4,8,12,16$.

Pupils were guided to pick 12 as the least common multiple because it is the least number that can be found in the multiples of 3 and 4 .

The researchers then guided the pupils to choose a whole rod to represent the least common multiple, which is 12 . The whole rod should be able to split into four (4) equal parts and at the same time three (3) equal parts. The researcher guided pupils to choose black and yellow as the whole. The researcher then asked pupils to choose purple to represent thirds and light green to represent fourths.

\begin{tabular}{|c|c|c|c|}
\hline \multicolumn{2}{|l|}{ Black } & \multicolumn{2}{|c|}{ Yellow } \\
\hline Purple & Purple & & Purple \\
\hline Light green & Light green & Light green & Light green \\
\hline
\end{tabular}

Figure 6. Cuisenaire rod in use.

The researcher then assisted pupils to take two purples for $2 / 3$ and one light green for $1 / 4$ out of the whole.

\begin{tabular}{|c|l|l|}
\hline \multicolumn{2}{|l|}{ Black } & \multicolumn{2}{l|}{ Yellow } \\
\cline { 1 - 2 } Purple & Purple & Light green \\
\cline { 1 - 2 }
\end{tabular}

Figure 7. Modeling 2/3 and 1/4.

The researchers further guided the pupils to change the whole rod, which is black and yellow for 12 whites, the two purples for 8 whites and one (1) light green for 3 whites.

\begin{tabular}{|c|c|c|c|c|c|c|c|c|c|c|c|}
\hline $\mathrm{W}$ & $\mathrm{W}$ & $\mathrm{W}$ & $\mathrm{W}$ & $\mathrm{W}$ & $\mathrm{W}$ & $\mathrm{W}$ & $\mathrm{W}$ & $\mathrm{W}$ & $\mathrm{W}$ & $\mathrm{W}$ & W \\
\hline $\mathrm{W}$ & W & $\mathrm{W}$ & W & W & $\mathrm{W}$ & W & $\mathrm{W}$ & W & W & $\mathrm{W}$ & \\
\hline
\end{tabular}

The researchers then asked pupils to join them to get 11 whites. Compare this to the original whole.

$$
\begin{array}{lllllllllll}
\text { W } & \text { W } & \text { W } & \text { W } & \text { W } & \text { W } & \text { W } & \text { W } & \text { W } & \text { W } & \text { W } \\
\text { Figure } 8 \text { Cuisenaire rod in use. } &
\end{array}
$$

Therefore, ${ }^{2} / 3+1 / 4=8 / 12+3 / 12={ }^{8+3} / 12=11 / 12$

The researchers used paper folding as her second method in solving the pupils' problem. In groups, the researcher gave pupils two sheets of papers for them to add $1 / 2+1 / 3$. The researcher guided the pupils to fold one paper into two equal parts horizontally and shaded one portion to represent $1 / 2$ as shown below in diagram A.

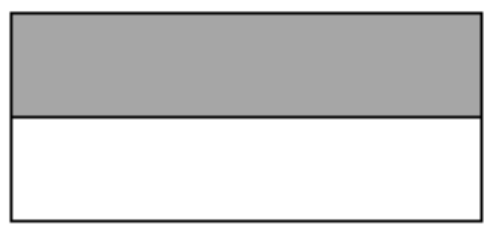

\section{$1 / 2$}

Figure 9. Illustration of $\frac{1}{2}$ paper folding.

The researchers again guided the pupils to fold the second paper vertically into three (3) equal parts and shaded one part to represent $1 / 3$.

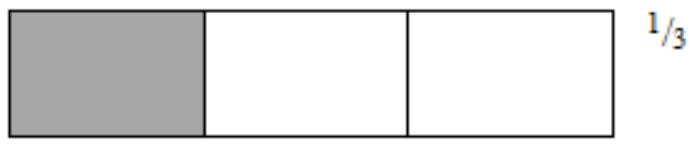

B.

Figure 10. Illustration of $\frac{1}{3}$ paper folding.

The researchers guided the pupils to fold the first paper (A) above vertically into three (3) equal parts and the shaded portion represents $3 / 6$ as shown in diagram $\mathrm{C}$ below.

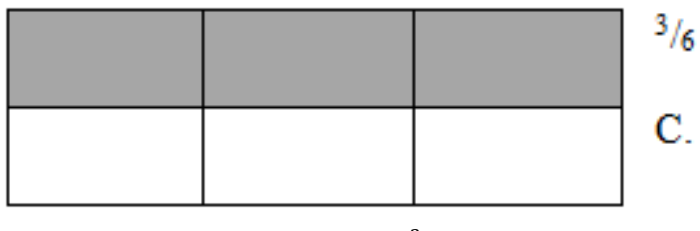

Figure 11. Illustration of $\frac{3}{6}$ paper folding.

The researcher again assisted them to fold the paper in diagram (B) above horizontally into 2 equal parts and the shaded portion represents $2 / 6$ as shown in figure $\mathrm{D}$ below.

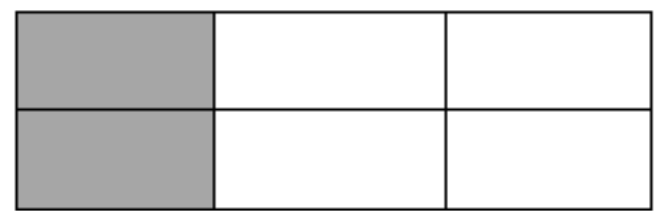

$2 / 6$

D.

Figure 12. Illustration of $\frac{2}{6}$ paper folding. 
The researcher then asked the pupils to add the shaded portions in (C) and (D) so that the shaded portions will be $5 / 6$. Therefore $1 / 2+1 / 3=3 / 6+2 / 6=5 / 6$

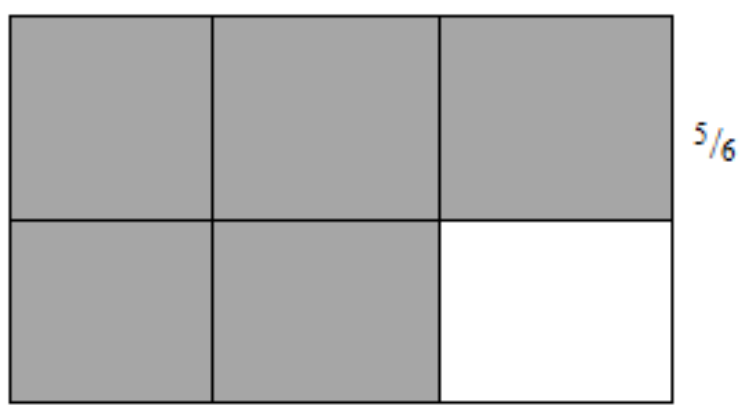

Figure 13. Illustration of $\frac{5}{6}$ paper folding.

After the careful implementation of the intervention, the researcher repeated the test that was conducted at the preintervention stage on the experimental group to ascertain the effectiveness of the intervention. The questions attracted the same scores and the pupils worked under the same conditions as the pre-test. This test after marking indicated clearly that, there was generally great improvement in their performance

The researcher used frequency table to compare the performance of pupils during pre-test and post-test processes that will also be used to analyze the results in the next chapter.

Before the actual intervention was carried out, a preintervention test was conducted to determine the pupils' level of understanding in adding unlike fractions. The results are shown on Table 1.

Table 1. Pre-Test Result.

\begin{tabular}{lll}
\hline Marks & Number of Pupils & Percentage (\%) \\
\hline 0 & 5 & 11 \\
1 & 13 & 16 \\
2 & 7 & 29 \\
3 & 7 & 16 \\
4 & 4 & 9 \\
5 & 4 & 9 \\
6 & 1 & 2 \\
7 & 1 & 2 \\
8 & 1 & 2 \\
9 & 2 & 4 \\
10 & 0 & 0 \\
Total & 45 & 100 \\
\hline
\end{tabular}

From the data obtained and recorded in Table 1, the pretest was scored over ten and 36 pupils representing $80 \%$ scored below the pass mark of 5 , only 4 pupils representing $9 \%$ obtained the pass mark of 5 whilst 5 pupils representing $11 \%$ obtained marks above the pass mark of 5 . However, no pupil scored 10 marks.

Having diagnosed the extent of the problem, the researcher also observed pupils' attendance, participation in class, their interest in Mathematics class and what have you, during and after the intervention activities. The researcher after observing presented the possible causes of pupils' difficulties in addition of unlike fractions in Figure 14.
60

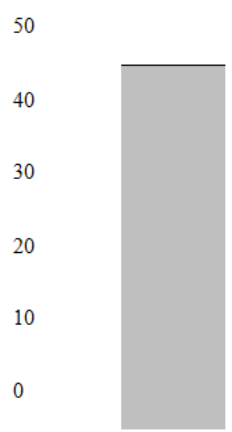

Absence of

of TLM

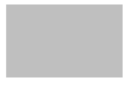

Absenteeism

among pupils

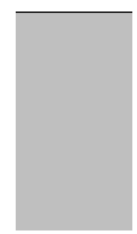

Inappropriate

teaching method

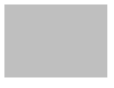

Inattentiveness

in class
Figure 14. Bar chart of possible causes of pupils' difficulties in mathematics.

After taking pupils through the intervention activities, parallel or similar test was designed and administered. The results are shown in Table 2

Table 2. Post Test Results.

\begin{tabular}{lll}
\hline Marks & Number of Pupils & Percentage (\%) \\
\hline 0 & 0 & 0 \\
1 & 1 & 2 \\
2 & 0 & 0 \\
3 & 2 & 4 \\
4 & 0 & 0 \\
5 & 3 & 7 \\
6 & 9 & 20 \\
7 & 5 & 11 \\
8 & 14 & 31 \\
9 & 3 & 7 \\
10 & 8 & 18 \\
Total & 45 & 100 \\
\hline
\end{tabular}

Table 2 shows that $3+9+5+14+3+8=42$ pupils representing 93.3\%, $7+20+11+31+7+18=94 \%$ obtained the pass mark of 5 . Four (4) pupils representing $0+$ $2+4+0=6 \%$ still scored marks below the pass mark of 5 . This shows that after the intervention, pupils' performance in addition of unlike fractions had improved significantly.

\section{Result and Discussions}

Comparing the pre-test and the post-test results in Tables 1 and 2 respectively, it is clear that while 36 pupils representing $80 \%$ obtained marks below the pass mark of 5 in the pre-test, only 9 pupils representing $20 \%$ obtained marks above the pass mark of 5 . From Table 2, 94\% of the pupils scored marks above the pass mark of 5 in the post-test as compared to $20 \%$ in the pre-test. The modal mark in the pretest is one (1), whilst in the post-test it is 8 . This means that in the pre-test, many pupils scored one mark, which is below the pass mark. However, many pupils obtained a score of eight marks, which is above the pass mark of 5 in the post- 
test. Therefore, the pupils' performance has improved significantly in adding unlike fractions after going through the intervention activities. It was also observed that pupils' interest, participation and attendance in Mathematics lessons had improved tremendously during and after the intervention activities and it in conformity with the findings of $[28,13$, 14].

\section{Conclusion}

There was remarkable improvement with use of Cuisenaire rod and paper folding in the ability of the pupils to add unlike fractions correctly after going through the practical activities of the intervention. Pupils' attendance and participation in mathematics lessons had also improved significantly. In addition, poor teaching methods, teaching and learning materials were not used during mathematics lessons. Teachers mostly taught using questions and answers method, and teacher centred method to teaching mathematics and that why the pupils had the difficulty to understanding the concept. However, it appears that the intervention activities were still not able to help all the pupils. Scores of the posttest by the pupils indicated that 3 pupils representing $6 \%$ obtained marks below the pass mark of 5 .

The study became necessary when it was observed that form one pupils of Chamba M/A Junior High School "A" could not add unlike fractions. The purpose of the study was to investigate the possible causes of this problem with the view of coming out with practical measures that could help minimized the situation. The researcher used direct observation and test as the main instruments to obtain solid information about their problems. The identified problems were systematically addressed at the intervention stage where a lot of activities were introduced to pupils to minimize the situation. This actually made a great impact on the pupils' achievement in mathematics hence increased their understanding in the addition of unlike fractions. Some few lessons learnt were that poor teaching methods, teaching and learning materials were not used during mathematics lessons. Teachers mostly taught using questions and answers method, and teacher centred method to teaching mathematics lessons.

The researcher is confident that the research work has contributed meaningfully to pupil's class performance not only in fractions but mathematics in general.

This study made a great impact on the pupils' performance after the research work. This is due to the fact that the researcher sacrificed to improvise Cuisenaire rods and papers folding as teaching and learning materials together with the activity method during the intervention period. Furthermore, appropriate methods of teaching and motivation helped to arouse and sustain the pupils' interest to understand the concept. The good results is that, pupils' performance was improved from $20 \%$ in the pre-test to $94 \%$ in the post-test

Based on the research findings, the researcher came out with, the following suggestions or recommendations which when considered will improve the situation the more.

First and foremost, adequate preparation and careful selection of teaching methods and activities should be given be much attention so as to enhance smooth delivery and pupils participation in lessons. Secondly, quizzes and group works should be encouraged to motivate pupils' active participation in mathematics lessons. Mathematics teachers should do well to get appropriate teaching and learning resources and make efforts to use them in class to enhance better understanding. The Ghana Education Service in consultation with the Ministry of Education should organize in-service training from time-to-time for Mathematics teachers to update their knowledge on the teaching of Mathematics. Finally, Ghana Education Service should also provide teaching and learning resources needed to all schools or pay teaching and learning materials allowances to enable teachers acquire materials for their lessons.

\section{References}

[1] MOE. (2010). Teacching syllabus for core mathematics. Accra: CRDD.

[2] Adu-Gyamfi, S. Donkoh, W. J. \& Adinkrah A. A. (2016). Eduational Reforms in Ghana. Past and Present. Journal of Education and Human Development 5 (3), 158-172

[3] NaCCA (2018). National Pre-tertiary Education Curriculum Framework for developing Subject Curricula, Cantonments, Accra

[4] Nabie, M. J., Raheem, K., Agbemaka, J. B., \& Sabtiwu, R. (2016). Multiple solutions approach (MSA): Conceptions and practices of primary school teachers in Ghana. International Journal of Research in Education and Science (IJRES), 2 (2), 333-344.

[5] Bouck, E. C., Park, J., Sprick, J., Shurr, J., Bassette, L.\& Whorley, A. (2017). Using the virtual-abstract instructional sequence to teach addition of fractions Research in Developmental Disabilities 70, 163-174

[6] Jordan, N. C., Hansen, N., Fuchs, L. S., Siegler, R. S., Gersten, R., \& Micklos, D. (2013). Developmental predictors of fraction concepts and procedures. Journal of Experimental Child Psychology, 116 (1), 45-58.

[7] National Mathematics Advisory Panel (2008). Foundations for success: The final report of the national mathematics advisory panel Washington, DC: U.S. Department of Education. http://dx.doi.org/10.1016/j.jecp.2013.02.001

[8] Hecht, S. A., \& Vagi, K. J. (2010). Sources of group and individual differences in emerging fraction skills. Journal of Educational Psychology, 102, 843-859. http://dx.doi.org/10.1037/a001982

[9] Misquitta, R. (2011). A review of the literature: Fraction instruction for struggling learners in mathematics. Learning Disabilities Research \& Practice, 26, 109-119. http://dx.doi.org/10.1111/j.1540-5826.2011.00330.x.

[10] Gersten, R. M., Chard, D., Jayanthi, M., Baker, S. K., Morphy, P., \& Flojo, J. (2009). Mathematics instruction for students with learning disabilities: A meta-analysis of 173E.C. Bouck et al. 
[11] Doabler, C. T., \& Fien, H. (2013). Explicit mathematics instruction: What teachers can do for teaching students with mathematics difficulties? Intervention for School and Clinic, 48, 276-285. http://dx.doi.org/10.1177/1053451212473141.

[12] National Center on Intensive Intervention (2016). Principles for designing intervention in mathematics. Washington, DC: Office of Special Education, U. S. Department of EducationRetrievedfrom,

http://www.intensiveintervention.org/sites/default/files/Princip _Effect_Math_508

[13] Browder, D. M., Jimenez, B. A., Spooner, F., Saunders, A., Hudson, M., \& Bethune, K. S. (2012). Early numeracy instruction for students with moderate and severe developmental disabilities. Research \& Practice for Persons with Severe Disabilities, 37, 308-320. http://dx.doi.org/10.2511/027494813805327205

[14] Root, J. R., Browder, D. M., Saunders, A. F., \& Lo, Y. Y. (2017). Schema-based instruction with concrete and virtual manipulative to teach problem solving to students with autism. Remedial and Special Education, 38, 42-52. http://dx.doi.org/10.1177/0741932516643592.

[15] Siegler, R., Carpenter, T., Fennell, F., Geary, D., Lewis, J., Okamoto, Y., Wray, J. (2010). Developing effective fractions instruction for kindergarten through 8th grade: A practice guide (NCEE 2010-4039). Washington, DC: National Center for Education Evaluation and Regional Assistance Retrieved from,

http://ies.ed.gov/ncee/wwc/pdf/practice_guides/fractions_pg 093010.pdf

[16] NCTM (2017)

[17] Shin, M., \& Bryant, D. P. (2015). Fraction intervention for students struggling to learnmathematics: A research synthesis. Remedial and Special Education, 36, 374-387. http://dx.doi.org/10.1177/0741932515572910.

[18] Butler, F. M., Miller, S. P., Crehan, K., Babbit, B., \& Pierce, T. (2003). Fraction instruction for students with mathematics disabilities: Comparing two teaching sequences. Learning Disabilities Research \& Practice, 18, 99-111. http://dx.doi.org/10.1111/1540-5826.00066.

[19] Jones, T. (2019). The Top 5 Reasons for using Manipulatives in the Classroom. Httpt://www.tljconsultinggroup.com Retrieved on $23 / 01 / 2020$

[20] Agrawal, J., \& Morin, L. L. (2016). Evidence-based practices: Applications of concrete representational abstract framework across math concepts for students with mathematics disabilities. Learning Disabilities Research \& Practice, 31, 34-44. http://dx.doi.org/10.1111/ldrp.12093

[21] Bouck, E. C., Satsangi, R., \& Park, J. (2017). The concrete- representational-abstract approach for students with learning disabilities. Remedial and Special Education. http://dx.doi.org/10.1177/0741932517721712 [Advanced Online Publication].

[22] T-TEL. (2015). Transforming teacher education and learning in Ghana Programme: Draft baseline survey report. Accra, Ghana: T-TEL/ Ministry of Education

[23] Boaler, J. \& Lamar, T. (2019). There is a Better way to Teach Students with learning Disabilities. https://www.time.com/5539300. Retrieved on 23/10/2020

[24] Kennedy, L. (2019). How to Add Fractions: 3 easy steps. https://www.prodigyame.com. Retrieved on 22/01/2020

[25] Obeng, A. K. B (2005), Core Mathematics for West Africa Secondary Schools and Colleges, Kumasi-Ghana: Approaches Ghana Ltd

[26] Winston, B. (2019). How to Teach Math with Cuisenaire Rod. https://www.sciecing.com. Retrieved on 22/01/2020

[27] Mooney, T. A., Whitlow, W. L. Au, Paul, E. N. and Edward, A. T. (2007). Knowledge and Understanding: USA. Learning Matters Ltd.

[28] Briggs, H. (2014). New Insight into how Children learn Math. https;//www.bbc.com. Retrieved on 22/01/2020

[29] Mak, A. (2018). 4 Reasons Students Don't pay Attention in Class. Why ands How. https://www.strenghsAsia. Com. Retrieved on 22/01/2020.

[30] Dotse, D. (2000). Mathematics and the Threshold of the New Millenium

[31] Aseidu, P (2011). AKI-OLA series, Accra: Aki-ola publications

[32] Brinks, M.(2019). How to Add and Subtract Fractions SAT/ACT prep online Guides and tips. https://www.blog.prepscholar.com. Retrieved on 22/01/2020

[33] Chang, S. H.; Lee, N. H. \&Koay, P. L. (2017). Teaching and Learning with Concrete-pictorial-abstract Sequence. A proposed model. The Mathematics Educator, 17 (1), 1-28

[34] Creswell, J. W. (2014). Research design: qualitative, quantitative and mixed methods approaches $\left(4^{\text {th }} \mathrm{ed}\right.$.), London and Califonia: SAGE Publications, Inc

[35] Creswell, J. W. (2009). Research design: qualitative, quantitative and mixed methods approaches ( $3^{\text {rd }}$ ed.). London

[36] Cohen, L., Manion, L. \& Morrison, K. (2007). Research Methods in Education (6th ed), Rout ledge Publishers (part)

[37] McMillan, J \& Schumacher, S. (2014) Research in Education, Evidence-Base Inquiry. Pearson Education Limited: England 